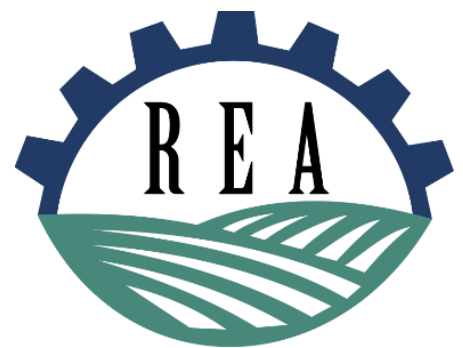

Revista de Economia e Agronegócio - REA

ISSN impresso: 1679-1614

ISSN online: $2526-5539$

Vol. 16 | N. 1 | 2018

EDITORIAL

\title{
COMO OS DADOS FALAM SOBRE O FUTURO?'
}

\author{
Eliseu Alves* \\ *Empresa Brasileira de Pesquisa Agropecuária (EMBRAPA), \\ Brasília, Distrito Federal, Brasil. \\ E-mail: eliseu.alves@embrapa.br
}

Os dados descrevem o passado para o historiador. Já o formulador de políticas públicas quer que os dados falem sobre o futuro, tema de suas amarguras. Vamos introduzir o assunto com parte da história inicial da Empresa Brasileira de Pesquisa Agropecuária - Embrapa, nos utilizando dos resultados de pesquisa sobre o Censo Agropecuário de 2006.

Inaugurada em 26 de abril de 1973, a Embrapa recebeu o DNPEA (Departamento Nacional de Pesquisa Agropecuária) com suas unidades de pesquisas, semelhantes em organização ao Instituto Agronômico de Campinas, com múltiplos focos e um corpo de funcionários predominantemente localizado nos Estados do Rio de Janeiro e Rio Grande do Sul, e em menor proporção presente no Paraná, Minas Gerais, Bahia, Pernambuco, Pará e Amazonas. Mediante seleção rigorosa, recebeuse autorização para incorporar os selecionados aos quadros da Embrapa, o que foi feito. Os não selecionados foram incorporados aos quadros do MAPA. Também foi preciso reorganizar as unidades de pesquisa do DNPEA. Note-se que o modelo de empresa pública deu à Embrapa muita flexibilidade operacional para realizar suas tarefas, sendo que os novos contratados ficariam ao abrigo da CLT. Quanto aos funcionários do DNPEA, estes poderiam permanecer no regime trabalhista em que se encontravam ou optar pelo da CLT (ALVES, 2010).

Todavia, restaram três questões: quais seriam as políticas para formação de pesquisadores e de organização de pesquisa, e quais as prioridades

\footnotetext{
${ }^{1}$ Versão do discurso proferido quando o autor foi agraciado com o título Doutor Honoris Causae pela Universidade Federal de Viçosa, em 17 de maio de 2017.
} 
gerais de pesquisa, centrada na produtividade da terra e, posteriormente, do trabalho. A diretoria da Embrapa, composta por José Irineu Cabral, Roberto Meireles, Edmundo Fontoura Gastal e Eliseu Roberto de Andrade Alves, sendo que no começo de 1974, Almiro Blumenschein substituiu Roberto Meireles, teve que tomar decisões envolvendo essas três questões.

O modelo de grande sucesso à época na agricultura eram os Estados Unidos da América, país de dimensões continentais, industrializado, urbanizado e em regime de competição. Julgou-se que o Brasil seguiria o caminho dos Estados Unidos no desenvolvimento de sua agricultura. Também seria industrializado, urbanizado, tendo a agricultura baseada na ciência e tecnologia. Assim, o papel da Embrapa era ser um instrumento dessa mudança. $O$ que precisaríamos saber, então, era quais os fundamentos do modelo americano que interessavam ao Brasil. Sem nenhum anúncio explícito, escolhemos os seguintes: pesquisadores de excelente nível, unidades de pesquisa focadas e prioridade de pesquisa sobre a produtividade da terra, pois estava ficando caro abrir novas fronteiras e já começava a resistência ao corte de árvores, embora muito tímida ainda. Entre alguns economistas agrícolas, julgava-se mais barato aumentar a produtividade da terra, doutrina que fundamentou a vida da Embrapa e a qual, mais tarde, foi incorporado o fator trabalho (ALVES, 2010).

Era necessário operacionalizar esses três fundamentos. Para pesquisadores de elevado nível, estabeleceu-se o programa de mestrado e doutorado nas universidades brasileiras e do exterior. Chegamos a ocupar metade das vagas de pós-graduação nas nossas universidades.

Em relação às unidades de pesquisa focadas, o primeiro nível de foco foi estabelecido pela sede da Embrapa. Foram definidos centros por produtos, como os de soja, gado de leite, caprinos e milho e sorgo, por biomas, como o de Cerrados, e por temas, como o Centro Nacional de Recursos Genéticos. O segundo nível de foco passou a ser de responsabilidade de cada unidade, de acordo com a área de planejamento da Embrapa, no nível de projeto.

$\mathrm{Na}$ produtividade da terra, a seleção de cultivares colocou em níveis idênticos a resposta do cultivar aos insumos modernos e ao estresse provocado por pragas e doenças. Em resumo, o novo cultivar tinha de fazer cada hectare produzir mais e também baixar o custo de produção por unidade de produto ${ }^{2}$. A produtividade do trabalho, medida pela área que cada trabalhador cultiva, é influenciada pela tecnologia mecânica. A

$2 \mathrm{P} / \mathrm{L}=(\mathrm{P} / \mathrm{A})^{*}(\mathrm{~A} / \mathrm{L})$, em que $\mathrm{P}$ representa a produção, $\mathrm{L}$, o trabalho aplicado, e $\mathrm{A}$, a área cultivada. É fácil verificar que o crescimento da produtividade do trabalho (P/L) é a soma dos crescimentos do rendimento $(\mathrm{P} / \mathrm{A})$ e da área que cada trabalhador cultiva $(\mathrm{A} / \mathrm{L})$, que indica o esforço do trabalho. Tecnologia poupa terra $(\mathrm{P} / \mathrm{A})$ e trabalho $(\mathrm{A} / \mathrm{L})$. Assim, o crescimento da produtividade do trabalho $(\mathrm{P} / \mathrm{L})$ é induzido pelo crescimento do rendimento e pelo esforço de cada trabalhador. Ou seja, pela tecnologia poupa-se tanto terra como trabalho. 
demanda por essa tecnologia depende da escassez do trabalho, da insegurança jurídica na esfera trabalhista e de outras complicações quanto à administração da mão de obra. Nos dias atuais, ela é muito forte. Muitas das tecnologias da área biológica e afins visam reforçar o poder das máquinas, como nos casos dos herbicidas e cultivares que facilitam a colheita mecânica. No âmbito propriamente dito de máquinas e equipamentos, há forte participação da pesquisa particular, e essa tem sido a tradição americana e europeia.

Em resumo, quanto à Embrapa, julgou-se que nossa agricultura iria seguir o caminho da americana, fundamentada na ciência e tecnologia, especializada e mecanizada, e que a ênfase da pesquisa seria voltada para o aumento da produção e da produtividade da terra e do trabalho. Evidentemente, procurou-se selecionar, no modelo americano, aspectos relevantes para o Brasil. Assim, tal modelo, devidamente interpretado, ajudou-nos a predizer o futuro da nossa agricultura sob o ponto de vista da pesquisa agrícola.

O Censo Agropecuário de 2006 foi esquadrinhado por uma equipe de pesquisadores da Embrapa (ALVES et al., 2013).

A tecnologia explicou grande parte do crescimento da agricultura: trabalho, 20\%; terra, 10\% e tecnologia, 70\% (medida por insumos como fertilizantes, agrotóxicos, rações, máquinas e equipamentos). Dados municipais (PAM, período 1970 a 2017) indicam que a área colhida está estagnada, com ligeira tendência a decréscimo no final do período, e, por isso, o rendimento da terra explicou o notável crescimento da produção. $\mathrm{O}$ aumento de rendimento depende também da nova tecnologia. Assim, a tecnologia domina a explicação do crescimento da agricultura. Além disso, o meio rural ficará despovoado. Em 1970, cerca de 44,06\% da população era rural e em 2010, 15,64\%. O despovoamento do meio rural não é maior em função das regiões Norte e Nordeste, que abrigaram 51,9\% de toda nossa população rural em 2010. Somente o Nordeste, 47,8\%. Para completar, Sudeste, 19\%; Sul, 13,8\% e Centro-Oeste, 5,3\% (ALVES; SOUZA; MARRA, 2017)

A dualidade da nossa agricultura se reflete no fato de que, em 2006, 11,4\% dos estabelecimentos que declararam ter produzido alguma coisa e usado terra para isso, produziram $87 \%$ do valor bruto da produção, enquanto $88,6 \%$ deles, os restantes, tão somente $13 \%$ daquele valor. Em número de estabelecimentos, quinhentos mil contra 3,9 milhões. Dos quinhentos mil, vinte e quatro mil corresponderam a $51 \%$ do valor bruto da produção. Ou seja, se a clonagem de estabelecimentos fosse viável, cerca de 48 mil, em 4,4 milhões, responderiam por toda a produção do ano de 2006 (ALVES; SOUZA; ROCHA, 2013).

Nos 3,9 milhões de estabelecimentos pobres, de acordo com dados do INCRA de 2012, estão 1.258 milhão de famílias assentadas pela reforma agrária, que realizaram o sonho de possuírem a terra, mas estão distantes de vencerem como produtores. As regiões Norte, Nordeste e Centro-Oeste 
concentram 97,51\% da área dos assentamentos e 91,87\% das famílias assentadas. A região Norte domina a reforma agrária: área dos assentamentos correspondente a $76,4 \%$ e famílias assentadas, 42\%; Nordeste, $12,02 \%$ e 32,59\%, respectivamente; Centro-Oeste, 9,09\% e $17,32 \%$, respectivamente (ALVES et al., 2015).

Quanto aos produtos que comandam o valor da produção, a agricultura é especializada em poucos, tendência também verificada em frutas e hortaliças. Os valores do aluguel da terra e dos salários, assim como as vantagens comparativas, exercem forte pressão para especialização em nível de estabelecimento e de região. Assim, o Centro-Oeste é dominado por grãos e florestas plantadas, e a pecuária de corte se move para a região Norte para fugir da competição com o cultivo de grãos. Nas regiões com produção de grãos, a pecuária libera terra pelo uso da tecnologia do confinamento. Diante disso, pergunta-se: como ficará a pecuária de corte nas regiões de grãos, de laranja e de cana de açúcar? Se há pasto, qual será o nível competitivo de produtividade? Nas proximidades das cidades, reinará a pecuária confinada? Enfim, será o custo de oportunidade e a vantagem comparativa que explicarão a organização da produção, tanto em nível de estabelecimento como em nível de região.

O encarecimento do trabalho em relação ao valor da produção pressionará a mecanização da agricultura, fato já documentado. Pelo Censo Agropecuário de 1995/96, o trabalho, em termos de dispêndios com trabalhadores, explicou 31,3\% do crescimento do valor bruto da produção e pelo Censo Agropecuário de 2006, 22,3\%, o que somente foi possível pela mecanização da agricultura. Visto de outra forma, o pessoal ocupado na agricultura equivaleu a 17,6 milhões, pelo Censo Agropecuário de 1970, atingiu o máximo de 23,4 milhões em 1985, para cair para 16,6 milhões em 2006, número este mais baixo que o de 1970, quando nossa agricultura era muito menor (ALVES et al., 2013).

A população mundial ainda cresce, mas as taxas estão cada vez mais reduzidas. Admite-se que, em 2050, a população mundial se estabilizará e passará a decrescer. Contudo, atualmente, o efeito do crescimento da população na demanda é pequeno e perderá relevância com o passar do tempo, e a renda per capita dominará a evolução agregada da demanda. O envelhecimento da população e a urbanização mudam o perfil de consumo, voltando-o para a proteína animal, frutas e hortaliças. Propriedades nutracêuticas serão exigidas na composição dos alimentos, na batalha pela boa saúde e pela longevidade.

Movida pela renda per capita, a demanda de alimentos, fibras e energéticos deverá crescer significativamente, bem como a produção, motivada pelo aumento da produtividade da terra e do trabalho. Porém, a via de expansão da área agricultada está esgotada, embora exista, no Brasil, bastante terra virgem disponível. Observa-se, então, que transformar pastagens em grãos não significa expandir a fronteira agrícola. 
A tecnologia explicará o crescimento da oferta de alimentos, fibras e energéticos. Ou seja, as instituições de pesquisa têm de dar prioridade às descobertas que baixam o custo e, simultaneamente, aumentam a produção, além de poupar trabalho e terra e evitar desperdícios em nível de estabelecimento e de consumo.

Quanto à tecnologia, é importante indagar se a ciência pode influenciar, pelas suas descobertas, a sua demanda. Implicitamente, admitimos que o mercado, tendo como base a variação dos preços dos insumos e dos produtos, induz o que as pesquisas básicas e aplicadas irão estudar. Todavia, alguns pesquisadores são influenciados pelo futuro distante e pelos sinais dos países desenvolvidos. Suas descobertas podem mudar as preferências do mercado por tecnologia. Nesse contexto, trata-se de inovações autônomas, algumas com a capacidade de mudar os rumos do mercado, pelos novos produtos que criam ou por novas maneiras de se realizarem tarefas antigas. Nesse terreno, nossa possibilidade de prever o futuro é muito limitada. Fosse essa possibilidade real, seria caso de se perguntar: por que não produzir a descoberta agora?

Com todas essas informações nas mãos, o que os números têm a dizer sobre o futuro de nossa agricultura?

Teremos uma agricultura poderosa, a segunda maior do mundo, exportadora e com o mercado interno abastecido a preços estáveis, sendo os seus dois maiores problemas a exportação do excedente acumulado e os 3,9 milhões de estabelecimentos marginalizados pela modernização. A base da agricultura será, como já é, a ciência e a tecnologia. Empregará muito pouco em nível de porteira, porque mecanizada, mas fora do estabelecimento exercerá importante papel no emprego, nas exportações e no desenvolvimento do Brasil. Ter-se-á um meio rural despovoado. Os centros de decisão da agricultura estarão localizados nas cidades, nossas e do exterior. Cerca de $90 \%$ da produção será comandada por $10 \%$ dos estabelecimentos; os grandes estabelecimentos, aqueles com renda bruta mensal de mais de duzentos salários mínimos, menos de $1 \%$ deles, serão responsáveis por 55\% do valor da produção. Pobreza, a maior parte dela nordestina, convivendo com a abundância! A política agrícola, que já espelha a dicotomia, continuará no mesmo caminho, tendo como instrumentos a agricultura familiar e o agronegócio, aqui centrada nas exportações e na pesquisa, sem as quais não se pode expandir a produção de forma competitiva, como exportador e com preços estáveis ou declinantes para o mercado interno.

A visão dominante afirma que a marginalização dos agricultores ocorre devido a nossa incapacidade de nos comunicar adequadamente com eles, sendo também esse o entendimento da política agrícola, e, por isso, se recomenda ampliar os investimentos em extensão rural.

Considera-se, porém, esse diagnóstico incorreto (ALVES, 2012). A hipótese de que a pequena produção está diante dos mesmos mercados é falsa. Em relação à grande produção, a pequena recebe menos pelo que vende, paga 
mais pelos insumos que compra e é discriminada no crédito rural, nos contratos que tem de assinar, no leasing, no aluguel de terra, na educação dos filhos e no acesso aos programas de saúde. Como vende mal a produção e compra os insumos por preços elevados, a tecnologia não é lucrativa para a pequena produção, e, por isso, não é adotada. Além disso, sem tecnologia não é possível resolver o problema da pobreza rural pela agricultura. Então, recorre-se às políticas de transferência de renda, como o bolsa família, a concessão de aposentadoria etc. Esses programas têm sido efetivos em aumentar a demanda interna por alimentos e em manter a população no meio rural e a paz social nas secas prolongadas do Nordeste. Contudo, mostram que não foi possível dar à pequena produção a oportunidade de escapar da pobreza rural pela agricultura. Num ambiente de imperfeições de mercado, não há como fazer a extensão rural cumprir o seu papel, porque a tecnologia, quando não gera lucro, é recusada pelos produtores.

No que diz respeito ao agronegócio, o papel do governo é crucial nas exportações, em pesquisa para aumentar a competitividade e na construção de infraestrutura para facilitar o escoamento da produção e o abastecimento interno. Reduzir o Custo Brasil é fundamental. Ademais, ninguém é grande exportador se também não for grande importador. Assim, o governo, no que tange à política externa, tem papel fundamental de batalhar pelas exportações, sabendo que as importações são armas de batalha decisivas.

A pressão pela sustentabilidade da agricultura, tanto no nível internacional como no interno, continuará muito forte. Ela foca nos recursos naturais e esquece dos agricultores. Agricultores pobres e sem esperanças não têm nem motivação nem recursos para adotar as tecnologias sustentáveis. Sendo assim, o foco recai nos produtores bemsucedidos, que estão em cerca de $11,4 \%$ dos estabelecimentos brasileiros, como a análise dos dados do Censo Agropecuário de 2006 mostrou (ALVES; SOUZA; SANTANA, 2016).

Chegamos a um ponto do desenvolvimento da agricultura em que os salários urbanos e rurais, para trabalhadores de mesmas habilidades, pouco diferem entre si; as decisões têm como base o custo de oportunidade; as famílias escolhem onde morar de acordo com suas preferências, sem serem tolhidas por restrições incontornáveis; e a solução do problema da pobreza rural pode estar nas cidades, pelo êxodo rural, ou na agricultura, pela tecnologia. A solução rural tem se mostrado inviável no mundo todo, não obstante os investimentos feitos na agricultura familiar e em políticas de transferência de renda a fim de ganhar tempo. A agricultura venceu a batalha da modernização, pela visão do excedente, seja ele destinado às exportações ou ao mercado interno, e não foi capaz de vencer as imperfeições de mercado, sendo que, assim, a tecnologia continuará discriminando a pequena produção. 


\section{REFERÊNCIAS}

ALVES, E. Embrapa: um caso bem sucedido de inovação institucional. Revista de Política Agrícola, ano 19, Edição Especial de Aniversário do Mapa - 150 anos, p. 65-73, 2010.

ALVES, E. Nosso problema de difusão de tecnologia. Revista de Politica Agrícola, ano 21, n. 1, p. 3-4, 2012.

ALVES, E.; SOUZA, G.; ROCHA, D. Desigualdades nos Campos na ótica do Censo Agropecuário 2006. Revista de Política Agrícola, ano 22, n. 2, p. 6775, 2013.

ALVES, E.; SOUZA, G.; ROCHA, D.; MARRA, R. Fatos Marcantes da Agricultura Brasileira. In: ALVES, E., SOUZA, G., GOMES, E. (eds.) Contribuição da Embrapa para Desenvolvimento da Agricultura Brasileira. Brasília, DF: Embrapa, 2013. p. 5-25.

ALVES, E.; SOUZA, G.; GARAGORRY, F.; MELLO, P. O sonho de produzir, assentados da reforma agrária da Bahia e do Rio Grande do Sul. Revista de Política Agrícola, ano 24, n. 3, p. 114-133, 2015.

ALVES, E. Desafios da pesquisa. Revista de Política Agrícola, ano 25, n. 4, p. 165-168, 2016.

ALVES, E.; SOUZA, G.; SANTANA, C. Pobreza e Sustentabilidade. Revista de Política Agrícola, ano 25, n. 4, p. 63-81, 2016.

ALVES, E.; SOUZA, G.; MARRA R. Uma viagem pelas Regiões e estados, guiada pelo Censo Agropecuário 2006. Revista de Política Agrícola, ano 26, n. 1, p. 113-150, 2017. 